\title{
Redox status, lipid peroxidation and protein oxidation levels in small ruminants
}

\author{
S. Cecchini1,5, G. Piccione' ${ }^{2}$, C. Saoca ${ }^{2}$, G. Giangrosso ${ }^{3}$, A.R. Caputo ${ }^{4}$ and F. Fazio ${ }^{2}$ \\ 1 University of Basilicata, Department of Sciences, Viale dell'Ateneo Lucano 10,85100 Potenza, Italy \\ ${ }^{2}$ University of Messina, Department of Veterinary Science, Polo Universitario dell'Annunziata, 98168 Messina, Italy \\ ${ }^{3}$ Experimental Zooprophylaxis Institute of Sicily "A. Mirri", 90121 Palermo, Italy \\ ${ }^{4}$ Indipendent Agronomist, 85050 Baragiano (PZ), Italy
}

KEY WORDS: goats, sheep, lipid peroxidation, protein oxidation, oxidative stress, redox balance

Received: 13 October 2017

Revised: 26 January 2018

Accepted: 19 February 2018

${ }^{5}$ Corresponding author:

e-mail: stefano.cecchini@unibas.it

\begin{abstract}
Redox status, lipid peroxidation and protein oxidative damage in blood samples of healthy goats and sheep were evaluated to show any possible correlation with daily milk yield or milk components, and between oxidant parameters and biomarkers of protein and lipid damage. Blood and milk samples were collected from fifty Maltese goats and forty Valle del Belice sheep. Redox status was assessed analysing the total oxidant status (TOS), the total antioxidant capacity (TAC), together with the nitric oxide radical (NO*) metabolite $\left(\mathrm{NO}_{\mathrm{x}}\right)$ content. Oxidative damage of lipids and proteins was analysed as thiobarbituric acid reactive substances (TBARS) and advanced oxidation protein products (AOPP), respectively. As for the comparison of the assessed oxidative stress (OS) parameters in the two species, only AOPP appeared significantly different $(P<0.01)$. While no correlation was observed between daily milk yield or milk components and the assessed OS parameters in both species, several correlations were shown among the assessed OS parameters, with differences appearing between the two species. In particular, TBARS levels were related to TOS in goats $(P<0.001)$ and to $\mathrm{NO}_{\mathrm{x}}$ in sheep $(P<0.001)$. Levels of AOPP were dependent on $\mathrm{NO}_{x}$ concentrations in sheep $(P<0.05)$ but they were correlated neither with TOS nor $\mathrm{NO}_{x}$ in goats $(P>0.05)$. So, the observed differences between two examined species seem to suggest that OS parameters are species-specific and a panel of different measurements based on various analytical methods should be considered to dutifully evaluate the OS.
\end{abstract}

\section{Introduction}

Reactive oxygen species (ROS) involved in several physiological functions are formed during cellular metabolic reactions (Nordberg and Arnér, 2001). When ROS are produced in excessive quantities exceeding the body antioxidant capacity, oxidative stress (OS) occurs. The presence of OS may lead to the oxidative damage of DNA, lipids and proteins (Lykkesfeldt and Svendsen, 2007). Consequently, the determination of OS indices allows the assessment of real status of physiological defences and the prevention of correlated pathologies. Although advanced methodologies for OS parameter evaluation are reported (Czauderna et al., 2011; Konieczka et al., 2014), in the clinical examination, in which biological samples are usually represented by plasma or serum, the applied methodologies should allow for a rapid and not expensive data collection. Therefore, in the present study the redox potential and biomarkers of lipid peroxidation and protein oxidation in blood serum of two breeds of dairy small 
ruminants were examined, adopting methodologies commonly applied in clinical examination. Redox potential was assessed measuring total oxidant status (TOS), as reactive oxygen metabolites (ROMs), and total antioxidant capacity (TAC), as ferric reducing antioxidant power (FRAP assay), together with the nitric oxide radical $\left(\mathrm{NO}^{\circ}\right)$ metabolite $\left(\mathrm{NO}_{\mathrm{x}}\right)$ content. Oxidized lipid and protein contents were measured as thiobarbituric acid reactive substances (TBARS) and advanced oxidation protein products (AOPP), respectively, as markers of lipid and protein damage. These methods, often in the form of commercial kits, are commonly applied both in humans and in animals (Lykkesfeldt and Svendsen, 2007; Giustarini et al., 2009; Celi et al., 2010). Although studies on OS are relatively new in veterinary medicine, in numerous papers OS involvement in several physiological and pathological conditions in livestock is highlighted (Lykkesfeldt and Svendsen, 2007; Celi, 2011). However, it is important to take into account the fact that OS indicators are also influenced by nutrition, and so the nutritional strategy can play a significant role in controlling the oxidant/ antioxidant status in ruminants (Gatellier et al., 2004; Celi et al., 2010; Di Trana et al., 2015).

So, the aim of the present study was to evaluate some OS biomarkers in healthy dairy goats and sheep raised in a typical breeding system of southern Italy, mainly through the evaluation of redox balance (TOS and TAC), together with $\mathrm{NO}^{*}$ metabolites $\left(\mathrm{NO}_{\mathrm{x}}\right)$. In addition, biomarkers of lipid and protein oxidations, like TBARS and AOPP, were also assessed in order to verify any possible relation among the applied methodologies and between lipid and protein oxidation products and oxidant contents, represented by TOS and $\mathrm{NO}_{\mathrm{x}}$. This could allow to estimate the lipid and protein damage by determining the levels of blood oxidants in small ruminants. Furthermore, the obtained data could be used as a valid tool for providing a detailed picture about the oxidative status of healthy animals or, more specifically, of species that have no reference values of OS biomarkers determined.

\section{Material and methods}

\section{Animals, location and sampling}

This study was conducted on a farm located in the province of Palermo $\left(37^{\circ} 7^{\prime} \mathrm{N}, 13^{\circ} 30^{\prime} \mathrm{E}\right.$; $734 \mathrm{~m}$ a.s.l.; Sicily, Italy) in winter 2016. All treatments, housing and animal care were carried out in accordance with the standards recommended by the EU Directive 2010/63/EU regarding the protection of animals used for scientific purposes, as recognized and adopted by the Italian law (DL 2014/26).

Fifty Maltese goats (2-3 year old, $43 \pm 2 \mathrm{~kg}$ body weight) and forty Valle del Belice sheep (2-3 year old, $64 \pm 3 \mathrm{~kg}$ body weight) were used in this study. The body condition score (BCS) was evaluated on the basis of the croup and lumbar regions (values between 1 and 5). All animals, subjected to the same management condition, were in the same milking period (second month of lactation) and reached a mean score of 3.5. Goats and sheep were fed polyphite meadows and were milked twice a day at 7:00 and 17:00. During milking, $300 \mathrm{~g}$ of a dietary supplement based on field bean, maize, barley and oats was provided to each animal. Chemical composition of diets is presented in Table 1. All animals were clinically healthy and free from internal and external parasites. The evaluation of health status was based on rectal temperature, heart rate, respiratory rate, appetite and faecal consistency (data not shown).

Table 1. Chemical composition of diets

\begin{tabular}{|c|c|c|}
\hline Composition & $\begin{array}{l}\text { Polyphite } \\
\text { meadows }^{1}\end{array}$ & $\begin{array}{l}\text { Dietary } \\
\text { supplement }\end{array}$ \\
\hline Dry substance, $\%$ & 19.2 & 88 \\
\hline Raw proteins ${ }^{2}, \%$ & 2.8 & 16.1 \\
\hline Raw lipids 2 , \% & 0.2 & 3.9 \\
\hline Raw fibres $2, \%$ & 28 & 33 \\
\hline Ashes $^{2}, \%$ & 2 & 7.9 \\
\hline Vit. E, $\mathrm{mg} \cdot \mathrm{kg}^{-1}$ & - & 75 \\
\hline Zinc (as $\mathrm{ZnO}), \mathrm{mg} \cdot \mathrm{kg}^{-1}$ & - & 155 \\
\hline Selenium (as $\left.\mathrm{Na}_{2} \mathrm{SeO}_{3}\right), \mathrm{mg} \cdot \mathrm{kg}^{-1}$ & - & 0.54 \\
\hline
\end{tabular}

${ }^{1}$ polyphite meadows were composed of field bean (Hedysarum coronarium L.), maize, barley and oats; ${ }^{2}$ expressed as $\%$ of dry substance matter

Blood samples were collected in the morning immediately after milking from the external jugular vein using Vacutainer tubes with no additive and, after clotting, sera were obtained by centrifugation (3000 rpm for $10 \mathrm{~min}$ at $4{ }^{\circ} \mathrm{C}$ ). Sera were stored at $-80{ }^{\circ} \mathrm{C}$ until further analyses (performed within 4 weeks after sampling).

Milk yield sampling was performed at the same day as blood sampling. Individual samples consisting of proportional volumes of morning and evening milking were collected and taken to laboratory under refrigeration for milk content analyses.

\section{Analytical methods}

TOS measured as ROMs was evaluated using the radical cation $N, N$-diethyl-para-phenylendiamine (DEPPD), as described by Alberti et al. (2000). The standard curve was constructed using tert-butyl hydroperoxide ( $t$-BHP) at concentrations 
ranging from 125 to $1000 \mu \mathrm{M}$. Data are expressed as $t$-BHP equivalents $(\mu \mathrm{M})$. TAC was evaluated performing the FRAP assay (Benzie and Strain, 1996). The standard curve was constructed using iron sulphate heptahydrate $\left(\mathrm{FeSO}_{4}{ }^{*} 7 \mathrm{H}_{2} \mathrm{O}\right)$ at concentrations ranging from 62.5 to $1000 \mu \mathrm{M}$. Data are expressed as $\mathrm{FeSO}_{4} * 7 \mathrm{H}_{2} \mathrm{O}$ equivalents $(\mu \mathrm{M})$. Moreover, TOS:TAC ratio was accepted as oxidative stress index (OSI) - an indicator of redox balance.

Nitric oxide radical ( $\mathrm{NO}^{\circ}$ ) was measured quantifying its stable metabolites $\left(\mathrm{NO}_{\mathrm{x}}\right)$, namely the sum of nitrite $\left(\mathrm{NO}_{2}^{-}\right)$and nitrate $\left(\mathrm{NO}_{3}^{-}\right)$, as indicated by Miranda et al. (2001). The standard curve was constructed using $\mathrm{NaNO}_{3}$ at concentrations ranging from 7.8 to $1000 \mu \mathrm{M}$. Data are expressed as $\mathrm{NaNO}_{3}$ equivalents $(\mu \mathrm{M})$.

Moreover, AOPP and TBARS were evaluated as markers of protein oxidation and lipid peroxidation, respectively.

AOPP were analysed following the original method of Hanasand et al. (2012). The standard curve was constructed using chloramine-T at concentrations ranging from 5 to $100 \mu \mathrm{M}$. The concentration of protein oxidation products was expressed as chloramine-T equivalents $(\mu \mathrm{M})$.
Milk samples were analysed using CombiFoss 6200 (Foss Electric, Padova, Italy) instrument for the assessment of protein, fat and lactose contents. The obtained data are presented as percentage.

\section{Statistical analysis}

All results are expressed as means \pm standard deviation (SD). Data were normally distributed $(P>0.05$; Kolmogorov-Smirnov test). Basic descriptive statistics, including the measures of central tendency and dispersion, were calculated (Table 2). The obtained analytical data were analysed by the unpaired Student's t-test in order to verify any possible significant differences between the two species. Values at $P<0.05$ were considered significant.

Linear regression analyses were performed in order to verify any possible correlations among the evaluated OS parameters and among the evaluated OS parameters with the daily milk yield and milk components of each animal. A probability level of $P<0.05$ was considered significant. All statistical analyses were performed using SigmaPlot for Windows Version 11.0 statistical software (Systat Software Inc., San Jose, CA, USA).

Table 2. Statistical evaluation of oxidative stress parameters in goats and sheep

\begin{tabular}{|c|c|c|c|c|c|}
\hline Parameters & Species & Mean \pm SD & $95 \%$ confidence interval & $25^{\text {th }}-75^{\text {th }}$ percentile & $\begin{array}{l}\text { Significance level } \\
\text { (P-value) }\end{array}$ \\
\hline \multirow[t]{2}{*}{ TOS } & goats & $779.80 \pm 235.90$ & $712.70 \pm 846.90$ & $588.00-919.40$ & ns \\
\hline & sheep & $721.30 \pm 259.50$ & $638.30 \pm 804.30$ & $545.70-823.10$ & \\
\hline \multirow[t]{2}{*}{ TAC } & goats & $317.90 \pm 35.68$ & $307.70 \pm 328.00$ & $294.10-338.10$ & ns \\
\hline & sheep & $272.50 \pm 54.91$ & $255.00 \pm 290.10$ & 250.30-301.80 & \\
\hline \multirow[t]{2}{*}{ OSI } & goats & $2.47 \pm 0.84$ & $2.24 \pm 2.71$ & $1.88-2.75$ & ns \\
\hline & sheep & $2.72 \pm 1.06$ & $2.38 \pm 3.06$ & $1.99-3.17$ & \\
\hline \multirow[t]{2}{*}{$\mathrm{NO}_{\mathrm{x}}$} & goats & $157.90 \pm 61.93$ & $139.70 \pm 176.10$ & $123.10-188.10$ & ns \\
\hline & sheep & $164.10 \pm 44.98$ & $149.70 \pm 178.50$ & $124.20-186.60$ & \\
\hline \multirow[t]{2}{*}{ AOPP } & goats & $31.34 \pm 10.63$ & $28.31 \pm 34.36$ & $24.42-36.96$ & $<0.01$ \\
\hline & sheep & $15.36 \pm 6.69$ & $13.23 \pm 17.50$ & $10.77-16.64$ & \\
\hline \multirow[t]{2}{*}{ TBARS } & goats & $1.00 \pm 0.18$ & $0.94 \pm 1.05$ & $0.87-1.13$ & ns \\
\hline & sheep & $1.13 \pm 0.33$ & $1.02 \pm 1.23$ & $0.90-1.37$ & \\
\hline
\end{tabular}

TOS - total oxidant status, as $t$-BHP equivalents $(\mu \mathrm{M})$; TAC - total antioxidant capacity, as $\mathrm{FeSO}_{4}{ }^{*} 7 \mathrm{H}_{2} \mathrm{O}$ equivalents $(\mu \mathrm{M})$; OSI - oxidative stress index, as TOS:TAC ratio; $\mathrm{NO}_{x}$ - nitric oxide metabolites, as $\mathrm{NaNO}_{3}$ equivalents $(\mu \mathrm{M})$; AOPP - advanced oxidation protein products, as chloramine-T equivalents $(\mu \mathrm{M})$; TBARS - thiobarbituric acid reactive substances, as malondialdehyde equivalents $(\mu \mathrm{M})$; ns - not significant

TBARS were measured according to the method described by Ermis et al. (2005). The product of lipid peroxidation was expressed in terms of malondialdehyde (MDA) equivalents $(\mu \mathrm{M})$ using an external standard calibration curve, linear in the range between 0.125 and $8 \mu \mathrm{M}$, obtained from MDA generation with 1,1,3,3-tetraethoxypropane (TEP) hydrolysis.

\section{Results and discussion}

In the present study some serum OS biomarkers in two breeds of different species of small ruminants, Maltese goats and Valle del Belice sheep raised in a typical breeding system, were investigated. TOS and TAC were evaluated in order to describe the 
serum redox potential together with $\mathrm{NO}^{\bullet}$ metabolites $\left(\mathrm{NO}_{\mathrm{x}}\right)$, a powerful oxidizing agent, while TBARS and AOPP, markers of lipid peroxidation and protein oxidation, were evaluated to describe the basal values of oxidative damages to serum lipid and protein components. To show any possible correlations between OS biomarkers and daily milk yield or milk components, milk samples were collected. It was found that milk yield was $2.6 \pm 0.171$ and $1.2 \pm 0.121$ for goats and sheep, respectively. The percentage contents of total protein, fat and lactose were $3.67 \pm 0.11,3.89 \pm 0.10$, $4.82 \pm 0.04$ and $6.10 \pm 0.08,6.93 \pm 0.07,4.62 \pm 0.03$ for goats and sheep, respectively. Although only AOPP levels among the evaluated OS biomarkers appeared significantly different $(P<0.01)$ between the two species (Table 2) and no correlation between daily milk yield or milk components and the assessed OS parameters in both species appeared, in the applied regression analyses some differences in the relation between markers of lipid and protein damage and oxidant substances were noted (Table 3).

Table 3. Correlation matrix among oxidative stress parameters of goats and sheep

\begin{tabular}{lllllll}
\hline & Species & TOS & TAC & OSI & $\mathrm{NO}_{x}$ & AOPP \\
\hline TAC & goats & 0.13 & - & & & \\
& sheep & 0.10 & - & & & \\
OSI & goats & $0.93^{* *}$ & 0.24 & - & & \\
& sheep & $0.86^{* *}$ & $0.36^{*}$ & - & & \\
$\mathrm{NO}_{x}$ & goats & 0.03 & 0.17 & 0.09 & - & \\
& sheep & $0.55^{* *}$ & 0.12 & $0.61^{* *}$ & - & \\
AOPP & goats & 0.21 & 0.23 & $0.29^{*}$ & 0.19 & - \\
& sheep & 0.21 & 0.26 & $0.32^{*}$ & $0.32^{*}$ & - \\
TBARS & goats & $0.44^{* *}$ & 0.01 & $0.45^{* *}$ & 0.11 & 0.18 \\
& sheep & 0.31 & 0.07 & 0.28 & $0.50^{* *}$ & 0.22 \\
\hline
\end{tabular}

TAC, OSI, NO ${ }_{x}$ AOPP, TBARS - see Table 2; *,** - indicate a statistic significance for $P<0.05$ and $P<0.001$, respectively

In the case of lipid peroxidation, TBARS seem to be related to $\mathrm{NO}_{\mathrm{x}}$ in sheep $(P<0.001)$ and to TOS in goat $(P<0.001)$, although the r-values were not high and amounted 0.50 and 0.44 , respectively. It may mean that the lipid damage depends on different oxidizing agents in the two studied species. In fact, TOS, assessed as reactive oxygen metabolites (ROMs), is mainly represented by hydroperoxides, whereas $\mathrm{NO}_{x}$ represent the final stable metabolites, namely nitrite $\left(\mathrm{NO}_{2}^{-}\right)$and nitrate $\left(\mathrm{NO}_{3}^{-}\right)$of the nitric oxide radical $\left(\mathrm{NO}^{\circ}\right)$. In contrast to results of lipid damage, protein oxidation levels, measured as AOPP, seem to be dependent only on the $\mathrm{NO}_{x}$ concentration in sheep $(P<0.05)$, whereas neither $\mathrm{NO}_{x}$ nor TOS seem to depict the protein damage in goats $(P>0.05)$, in which protein oxidation levels are related only with OSI $(P<0.05)$. The lack of correlation with the investigated oxidative substances in goats may suggest that neither $\mathrm{NO}_{\mathrm{x}}$ nor TOS are useful to describe protein damage measured as AOPP, arisen from the reaction between plasma proteins and chlorinated oxidants mediated by a neutrophil enzyme myeloperoxidase (Noyan et al., 2006). Thus, it can be assumed that other OS biomarkers may be used to better describe the protein oxidation damage or to more easily correlate with this parameter.

In our previous study on athletic horses, it was shown that both TBARS and AOPP levels depend on both TOS and $\mathrm{NO}_{x}$ concentrations, making them a valid tool to estimate lipid and protein damage by oxidant substances or their metabolites (Fazio et al., 2016). In the present results the observed differences between the two species of small ruminants, and between the small ruminants and horses may indicate that there is a species-specific response to OS parameters.

Such biomarkers expressing the blood redox potential as TOS and TAC, are correlated neither in sheep nor in goat, unlike in other animal species, including fish (Po et al., 2013; Fazio et al., 2015, 2016). OSI, the indirect parameter describing the redox balance, is highly correlated with TOS in both species $(P<0.001)$ and with TAC only in sheep $(P<0.05)$. Moreover, OSI is also correlated with AOPP both in goats and sheep $(P<0.05)$, and with TBARS only in goat $(P<0.001)$. According to Nisar et al. (2013), a better knowledge of lipid peroxidation and protein oxidation processes is needed not only for proper livestock management but also for ensuring the quality and safety of livestock products intended for human consumption.

Studies on OS are intensively conducted. However, in comparison to human medicine, only a limited number of effects of OS in livestock have been investigated. Thus, the characterization of easily used biomarkers, as those applied in the present study, could be used to study redox homeostasis and OS in veterinary medicine. In ruminants, a relationship between oxidative stress, chronic diseases and physiological stage (Celi, 2011) and a link between energy balance, metabolism, diet and oxidant/antioxidant balance are evidenced (Celi and Gabai, 2015). Moreover, it was found that in those animals dietary antioxidant components may play a pivotal role in blood redox homeostasis and affect production traits (Gatellier et al., 2004; Di Trana et al., 2015). 
Anyway, in contrast to human medicine, the lack of reference values for OS biomarkers in veterinary science makes it difficult to determine whether and when animals are experiencing OS. Furthermore, the identification of OS biomarkers responsible for the observed lipid peroxidation and protein oxidation levels in each species is crucial to understand the mechanisms that lead to oxidation of cellular components. In order to identify the right OS biomarkers for each species, a detailed evaluation and comparison of commonly used ones are essential. Therefore, in the present study the appropriate oxidant biomarker able to describe the protein damage in sheep was not identified. So, in this matter, our results are in agreement with the results of Celi (2011). According to this author, in veterinary medicine the 'ideal' biomarker does not exist and a panel of measurements is crucial to dutifully evaluate OS changes.

\section{Conclusions}

A better knowledge of lipid and protein oxidation processes is crucial for proper livestock management and, as a consequence, the sufficient quality of livestock products. So, basing on the fact that oxidative stress (OS) parameters are speciesspecific further studies are necessary to identify the appropriate biomarkers able to assess OS in small ruminants. These studies should be conducted in different physiological stages and in different rearing systems. Furthermore, the possibility to evaluate OS directly from blood will allow to provide simple and trustworthy methods of measuring the OS.

\section{References}

AlbertiA., Bolognini L., Macciantelli D., Caratelli M., 2000. The radical cation of $\mathrm{N}, \mathrm{N}$-diethyl-para-phenylendiamine: a possible indicator of oxidative stress in biological samples. Res. Chem. Intermed. 26, 253-267, https://doi.org/10.1163/156856700X00769

Benzie I.F.F., Strain J.J., 1996. The ferric reducing ability of plasma (FRAP) as measure of "antioxidant power": the FRAP assay. Anal. Biochem. 239, 70-76, https://doi.org/10.1006/ abio.1996.0292

Celi P., 2011. Biomarkers of oxidative stress in ruminant medicine. Immunopharmacol. Immunotoxicol. 33, 233-240, https://doi.org /10.3109/08923973.2010.514917

Celi P., Di Trana A., Claps S., 2010. Effects of plane of nutrition on oxidative stress in goats during the peripartum period. Vet. J. 184, 95-99, https://doi.org/10.1016/j.tvjl.2009.01.014

Celi P., Gabai G., 2015. Oxidant/antioxidant balance in animal nutrition and health: the role of protein oxidation. Front. Vet. Sci. 2, 48, https://doi.org/10.3389/fvets.2015.00048
Czauderna M., Kowalczyk J., Marounek M., 2011. The simple and sensitive measurement of malondialdehyde in selected specimens of biological origin and some feed by reversed phase high performance liquid chromatography. J. Chromatogr. B 879 , 2251-2258, https://doi.org/10.1016/j.jchromb.2011.06.008

Di Trana A., Bonanno A., Cecchini S., Giorgio D., Di Grigoli A., Claps S., 2015. Effects of Sulla forage (Sulla coronarium L.) on the oxidative status and milk polyphenol content in goats. J. Dairy Sci. 98, 37-46, https://doi.org/10.3168/jds.2014-8414

Ermis B., Yildirim A., Örs R., Tastekin A., Ozkan B., Akcay F., 2005. Influence of smoking on serum and milk malondialdehyde, superoxide dismutase, glutathione peroxidase, and antioxidant potential levels in mothers at the postpartum seventh day. Biol. Trace Elem. Res. 105, 27-36, https://doi.org/10.1385/ BTER:105:1-3:027

Fazio F., Cecchini S., Saoca C., Caputo A.R., Lancellotti M., Piccione G., 2016. Relationship of some oxidative stress biomarkers in Jumper horses after regular training program. J. Equine Vet. Sci. 47, 20-24, https://doi.org/10.1016/j.jevs.2016.07.014

Fazio F., Piccione G., Saoca C., Caputo A.R., Cecchini S., 2015. Assessment of oxidative stress in Flathead mullet (Mugil cephalus) and Gilthead sea bream (Sparus aurata). Vet. Med. 60, 691-695, https://doi.org/10.17221/8583-VETMED

Gatellier P., Mercier Y., Renerre M., 2004. Effect of diet finishing mode (pasture or mixed diet) on antioxidant status of Charolais bovine meat. Meat Sci. 67, 385-394, https://doi.org/10.1016/j. meatsci.2003.11.009

Giustarini D., Dalle-Donne I., Tsikas D., Rossi R., 2009. Oxidative stress and human diseases: origin, link, measurement, mechanisms, and biomarkers. Crit. Rev. Clin. Lab. Sci. 46, 241-281, https://doi.org/10.3109/10408360903142326

Hanasand M., Omdal R., Norheim K.B., Gøransson L.G., Brede C., Jonsson G., 2012. Improved detection of advanced oxidation protein products in plasma. Clin. Chim. Acta 413, 901-906, https://doi.org/10.1016/j.cca.2012.01.038

Konieczka P., Rozbicka-Wieczorek A.J., Więsyk E., Smulikowska S., Czauderna M., 2014. Improved derivatization of malondialdehyde with 2-thiobarbituric acid for evaluation of oxidative stress in selected tissues of chickens. J. Anim. Feed Sci. 23, 190-197, https://doi.org/10.22358/jafs/65709/2014

Lykkesfeldt J., Svendsen O., 2007. Oxidants and antioxidants in disease: Oxidative stress in farm animals. Vet. J. 173, 502-511, https://doi.org/10.1016/j.tvjl.2006.06.005

Miranda K.M., Espey M.G., Wink D.A., 2001. A rapid, simple spectrophotometric method for simultaneous detection of nitrate and nitrite. Nitric Oxide 5,62-71, https://doi.org/10.1006/ niox.2000.0319

Nisar N.A., Sultana M., Waiz H.A., Para P.A., Dar S.A., 2013. Oxidative stress - threat to animal health and production. Int. J. Livest. Res. 3, 76-83

Nordberg J., Arnér E.S.J., 2001. Reactive oxygen species, antioxidants, and the mammalian thioredoxin system. Free Radic. Biol. Med. 31, 1287-1312, https://doi.org/10.1016/S08915849(01)00724-9

Noyan T., GülerA., Şekeroğlu M.R., Kamaci M., 2006. Serum advanced oxidation protein products, myeloperoxidase and ascorbic acid in pre-eclampsia and eclampsia. Aust. N. Z. J. Obstet. Gynaecol. 46, 486-491, https://doi.org/10.1111/j.1479828X.2006.00647.X

Po E., Williams C., Muscatello G., Celi P., 2013. Assessment of oxidative stress biomarkers in exhaled breath condensate and blood of Thoroughbred foals. Vet. J. 196, 269-271, https://doi. org/10.1016/j.tvjl.2012.08.018 